\title{
A DIRECTIVE TYPE OF RADIO BEACON AND ITS APPLICATION TO NAVIGATION.
}

\author{
By F. H. Engel and F. W. Dunmore.
}

ABSTRACT.

This paper deals with a method of guiding a ship or airplane by means of radio signals sent from a particular type of directive radio beacon. The principle of operation of this beacon is described. Briefly it consists of two transmitting coil antennas arranged at an angle of about $135^{\circ}$ with respect to each other. Signals from a transmitting set are first impressed on one coil antenna and then on the other, the change being made once every second. Waves are thus intermittently propagated directively from each coil, the intensity of the emitted wave with respect to the plane of each coil varying in accordance with a figure-of-eight. An airplane or ship equipped with an ordinary receiving set if located on any bisector of the angles formed between the two coils will receive signals of equal intensity from both of them. Thus a definite course may be held in thick or foggy weather simply by navigating so that the signal strength from the two coils remains equal.

Results of actual tests both on shipboard and on an airplane are given. In one test the double-coil directive-radio beacon was located at the Bureau of Standards. Observations were made on the U. S. Lighthouse tender Maple along a course which extended east and west at a point on the Potomac River about $56.4 \mathrm{~km}$ (35 miles) south of Washington. At this point there was found to be a zone of equisignals about a mile wide, in which sector no noticeable difference in the intensity of the signals received from the two coils could be noticed. Outside this sector, however, the two signals were noticeably unequal in intensity.

Interesting results were obtained as a result of tests made on an airplane. It was found that the directive receiving characteristic of an ordinary trailing wire antenna caused an apparent shift of the equisignal zone in the direction of flight of the airplane when the airplane was flying at right angles to the zone of equal signals. The use of a heavy antenna weight (which caused the antenna to hang more nearly vertical) eliminated this zone shifting effect.

The point is made that while this aid to navigation may be effective only over definite routes or courses it has the advantage over other methods of direction finding in that no special receiving apparatus is necessary, and that it gives an immediate indication of any alteration in the course caused by drift from wind or tide.

\section{CONTENTS.}

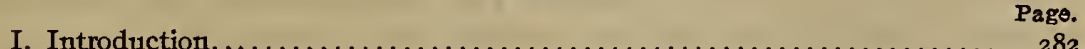

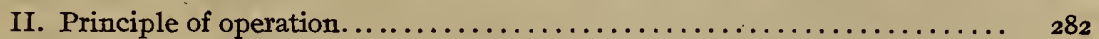

III. Preliminary experiments conducted at the Bureau of Standards....... 286

IV. Experiments conducted at McCook Field .................. 290

V. Summary . . . . . . . . . . . . . . . 


\section{INTRODUCTION.}

The problem of improving the safety of marine and aerial navigation in time of fog and poor visibility has always been an important one. Many aids to such navigation have been established, one of the latest and most effective of which has been the radio-direction finder installed on shipboard and used in conjunction with the radio beacon installed on light vessels. ${ }^{1}$

It is the purpose of this paper to describe a means for increasing the safety of both marine and aerial navigation, which was suggested by P. D. Lowell and which was recently developed by the Bureau of Standards in cooperation with the United States Signal Corps and the United States Air Service. Although somewhat restricted in its application, the simplicity of the method makes it of special value in many instances. This is especially true in cases where a ship or airplane wishes to navigate along a definite route, such as from Nantucket Shoals Light Vessel to Ambrose Channel Light Vessel. By means of the method to be described this result may be realized regardless of visibility conditions and without dependence on landmarks or the magnetic compass. No apparatus except an ordinary radio receiving set is needed on the ship or airplane.

\section{PRINCIPLE OF OPERATION.}

The method makes use of the directive transmitting properties of a coil antenna. A coil antenna is directional when used as a transmitting antenna, much as it is when used as a receiving antenna; that is, the familiar figure-of-eight directive characteristic is obtained. For example, suppose a coil antenna is to be located at $O$, Figure $\mathrm{I}$, with its plane along the line $E D$. Maximum transmission from it will take place along the line $E D$ and minimum transmission along the line $O^{\prime} Y$. A receiving set moved through the arc $D^{\prime} C^{\prime} B^{\prime} A^{\prime} O^{\prime}$ would receive signals whose strength would be proportional to the distances $O D, O C, O B$, and $O A$, respectively. At the point $O^{\prime}$, however, no signal will be received.

In the system being described two transmitting coil antennas are arranged at an angle of $135^{\circ}$ with respect to each other, such

\footnotetext{
${ }^{1}$ See "Direction and position finding by wireless," by R. Keen, The Wireless Press, I922; and B. S. Sci. Papers No. 428, The Radio Direction Finder and Its Application to Navigation, by F. A. Kolster and F. W. Dunmore, and Radio Fog Signals and Their Use in Navigation in Connection with the Radio Direction Finder (second edition), by George R. Putnam, Commisșioner of Lighthouses, Government Printing Office, r923.
} 
as shown at $A$ and $T$ in Figure 2. These coil antennas are arranged to be connected alternately to a radio transmitting set $W$ by means of a special switch $S$ which is thrown rapidly from one closed position to the other. Waves are thus intermittently propagated directively from each coil, the intensity with respect to the plane of the coil varying in accordance with a figure-of-eight

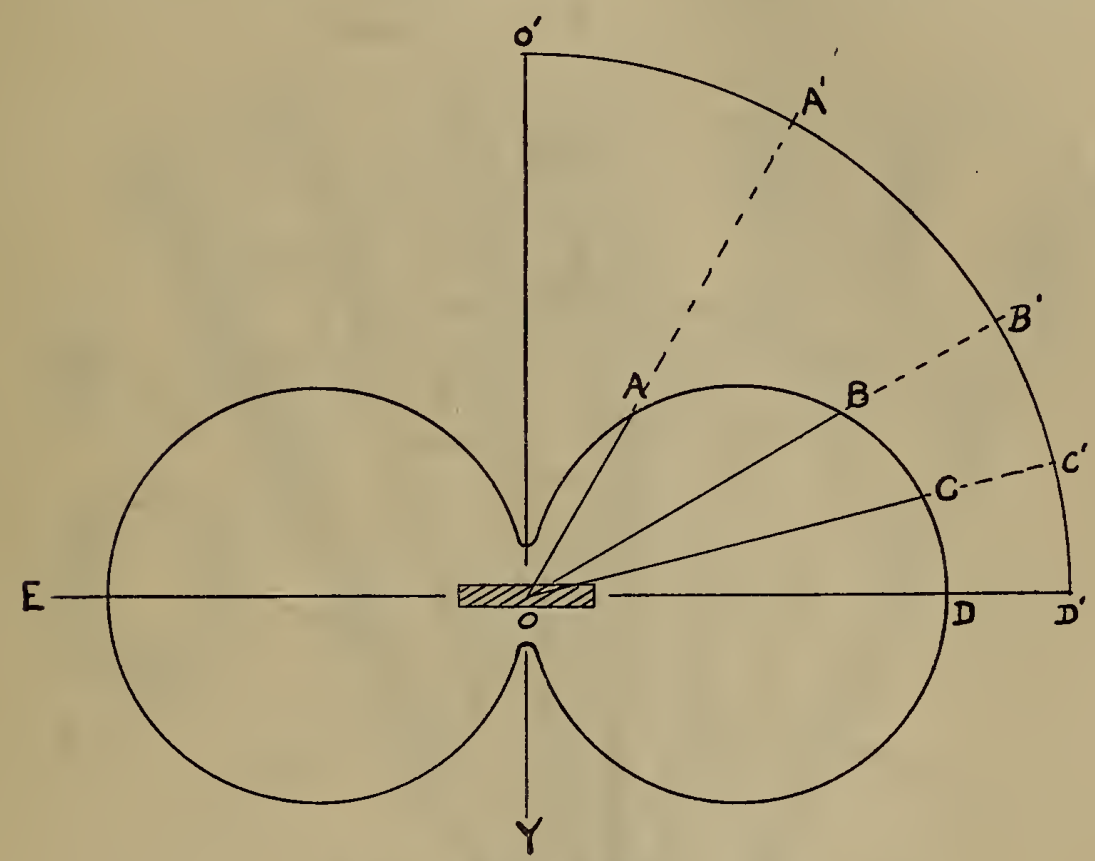

FIG. I.-Directive transmission characteristic of coil antenna.

as shown by the circles $A^{\prime}, A^{\prime}$, and $T^{\prime}, T^{\prime}$. The coil aerials are represented by the lines $a a$ and $t$. Thus, a receiving set located anywhere along the line $O Y$ would receive a signal proportional to the length of the line $O M$ from coil $t t$ and another a few seconds later of intensity proportional to the length of the line $O Q$ from coil $a a$. It is apparent, therefore, that along the line $O Y$ the signals from coil $t t$ are more than twice as strong as those from coil $a a$. A receiving set located along the line $O X$ will receive signals of equal intensity from both coils, since (as it is the bisector of the angle formed by the two coils) the distance $O P$ is the same for both coils. A similar condition exists along the lines $O V, O K$, and $O L$. It is apparent, therefore, that if the receiving set is moved to any other points than those along these lines signals of unequal intensity will be received from the two coils. Thus, a ship or airplane equipped with an ordinary receiving set 


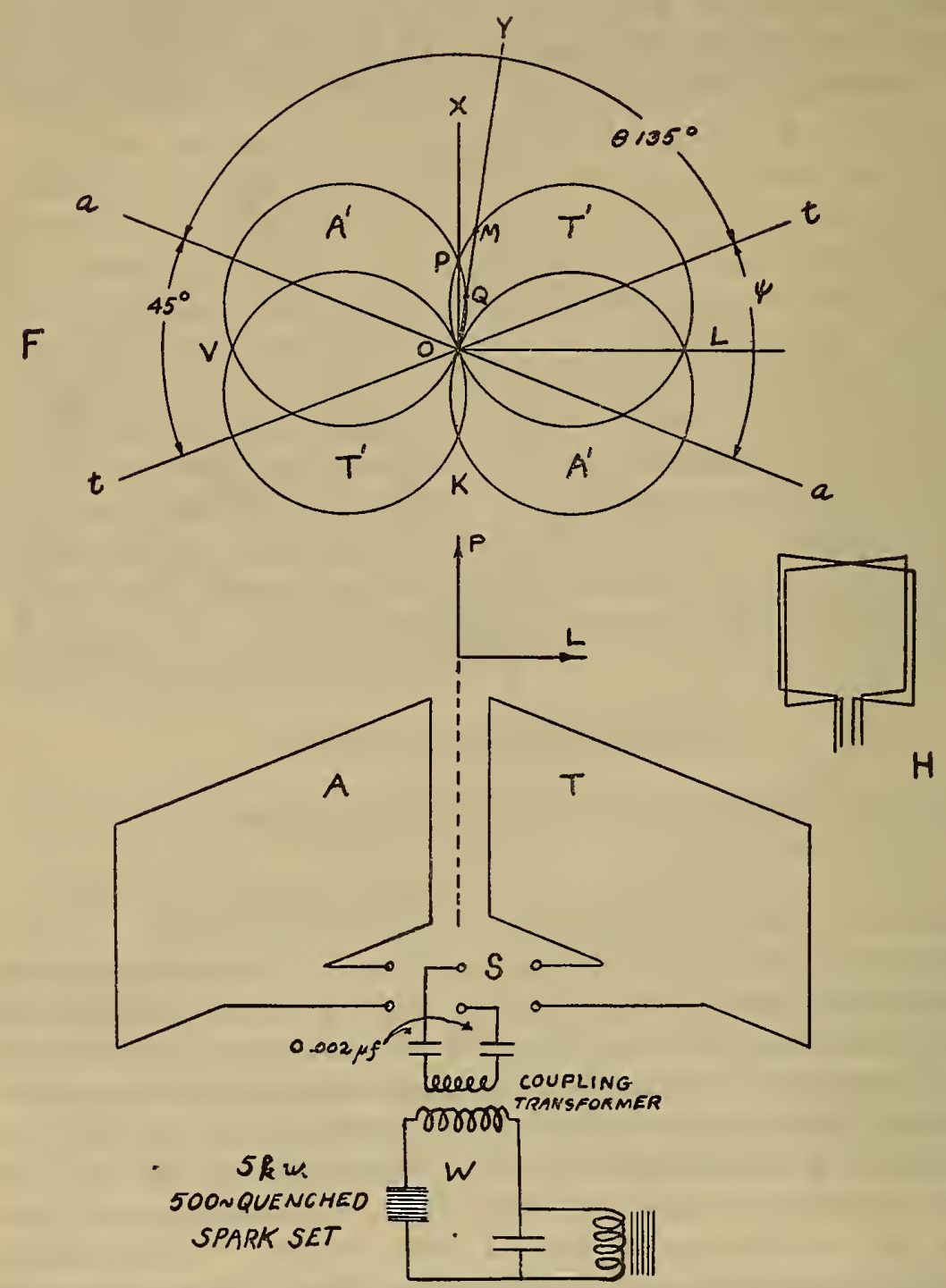

FIG. 2.-Principle of operation of equisignal double-coil antenna transmitting apparatus. 
navigating so as to keep the signals received from $a a$ and $t t$ of equal intensity will be going toward or away from the point $O$ or position where the two-coil antenna transmitting sets are located.

Figure 3 illustrates by a different method the principle involved in which the degree of shading indicates the relative signal

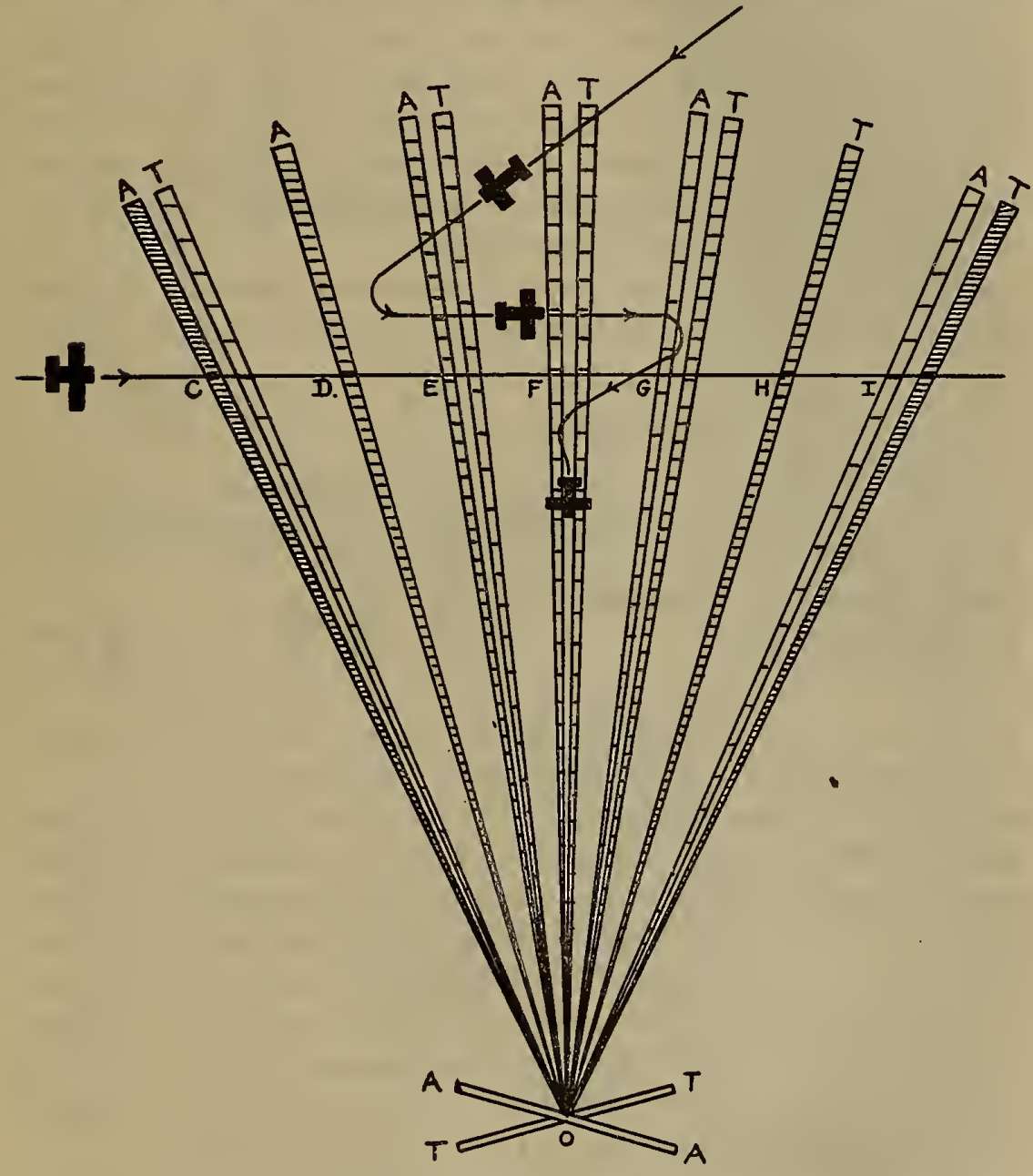

FIG. 3.-Airplane guided by equisignal zone.

Amount of cross section at any point shows the relative intensity of the signals received at that point from the two coils " $A$ " and " $T$."

intensity as received at any point from the two transmitting coil antennas $A$ and $T$. Thus, an airplane at $C$ would receive a loud signal from coil $A$ and a weak one from coil $T$. At $D$ the signal from $A$ is not as strong as at $C$, and the signal from $T$ has become inaudible. At $E$ the $A$ signal is still weaker and the $T$ signal 
is heard again faintly. At $F$ both signals are equal, and so on. The airplane coming in from the right is shown picking up the equisignal zone and following it in to $O$.

\section{PRELIMINARY EXPERIMENTS CONDUCTED AT THE BUREAU OF STANDARDS.}

Initial experiments were conducted with a view to obtaining data on the behavior of loop transmitting coil antennas; for example, sharpness of their maximum and minimum, best method of coupling to the primary of the spark transmitting set for maximum radiation, the decrement of the emitted wave, and the range to be expected with a given input.

Figure 4 shows the first type of double-coil antenna as tried out by the authors at the Bureau of Standards. Each coil con-

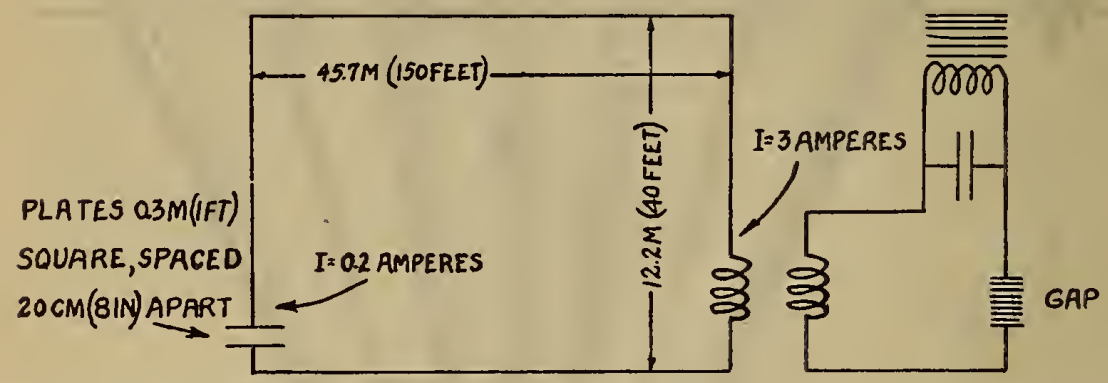

FIG. 5.-Coil antenna circuit found to give good radiation, but possessing undesirable directive properties for equisignal transmission.

sisted of two turns wound on a frame about $6.09 \mathrm{~m}$ (20 feet) square. The coils were arranged so that the angle between them could be varied in order to determine experimentally the best angle. Both coils could also be rotated simultaneously about the telegraph pole as an axis. This simplified the tests, as it enabled the receiving operator to remain stationary while the angular positions of the coils were transmitted to him as the coils were rotated. In this manner the width of the equisignal zone could. be determined and the nature of the transmission studied.

For tests at greater distances than were possible with the 6.09 $\mathrm{m}$ (20 feet) coils much larger single-turn fixed coil antennas, as shown in Figures 5 and 6, were used. With these coil antennas the directional characteristics were found to be a function of the current distribution in the coils. This is illustrated in the figures. The current distribution was found to be a function of the wave length as well as the circuit used. A coil antenna was connected as shown in Figure 5 and current readings made at various positions in the coil. It was found that the range of the coil when so 


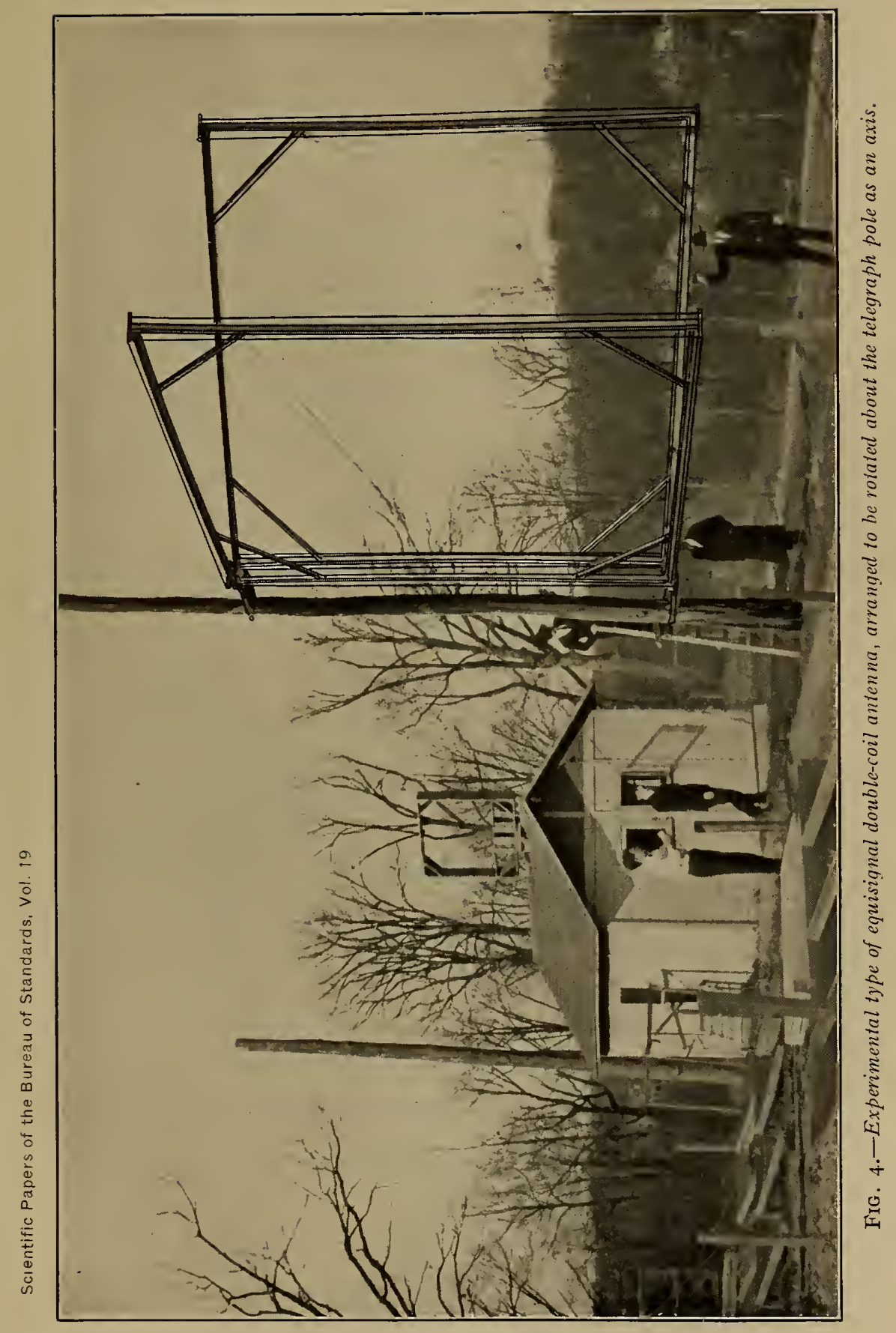


connected was much greater than when connected as shown in Figure 6 , but the desired directional characteristics were destroyed due to the unequal current distribution in the coil antenna. The coil connection shown in Figure 6 gave the best range while retaining the desired directional property. In all subsequent tests the method of connection shown in Figures 2 and 6 , and a frequency of 300 kilocycles ( $\mathrm{I}, 000 \mathrm{~m})$, was used.

The decrement of the emitted wave was found to be very small, being less than 0.05 . The efficiency of transmission obtained in the crossed-coil method is low, since the coils are set near their minima with regard to the receiving station. In order to increase the efficiency and range, an attempt was made to use coil antennas crossed at an angle of $45^{\circ}$, but the loss in sharpness of the equisignal zone was not balanced by the increase in range obtained.

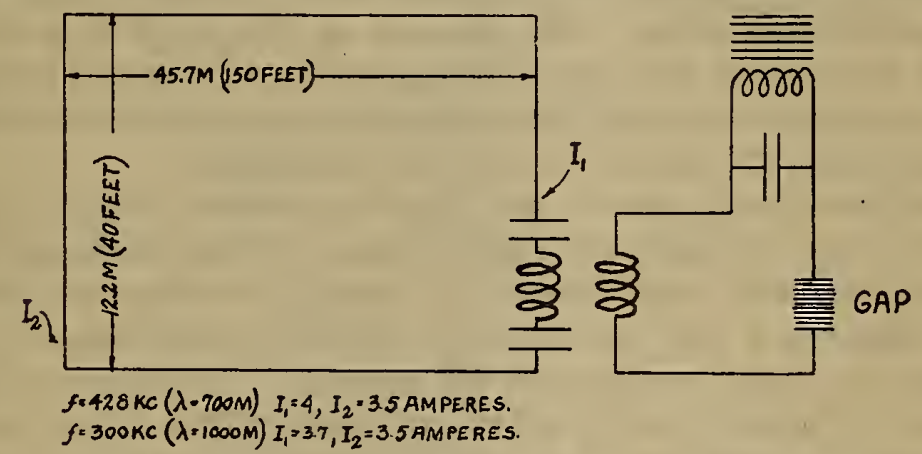

FIG. 6.-Coil antenna circuit found to be most satisfactory for equisignal transmission.

With these loops a 2-kilowatt quenched spark transmitting set was used, a d. p. d. t. switch being used to throw from one loop to the other. The connections used are shown in Figure 2. The letter "A" was sent while the secondary of the oscillation transformer was connected to coil $A$, and the letter " $T$ " when it was connected to coil $T$. Observations were made at points about I $1.3 \mathrm{~km}$ ( 7 miles) from the Bureau of Standards and located on a line perpendicular to the supposed line of equal signals. Audibility measurements made at these points proved the existence of a narrow zone of equal signals at a point which coincided roughly with the line determined from the geometric position of the loops.

In order to measure the exact width of the equisignal zone at a considerable distance from the transmitting coil antennas, a receiving set was installed on the U. S. Lighthouse tender Maple and a course run perpendicular to the zone of equisignals about $56.4 \mathrm{~km}$ (35 miles) from Washington.

$66863^{\circ}-24-2$ 
With the cooperation of the Bureau of Lighthouses a portable radio receiving set was installed on board the Maple and observations made continuously while the vessel was covering the distance from Metomkin Point to Mathias Point (see fig. 7).

Signals were transmitted from the Bureau of Standards by means of two single-turn coil antennas 45.75 by $15.25 \mathrm{~m}$ (I5o by 50 feet) crossed at a $143.5^{\circ}$ angle and alternately connected to a 2 -kilowatt quenched spark transmitting set. The coils were so tuned that the emitted wave frequency was approximately 300 kilocycles $(1,000 \mathrm{~m})$, the antenna current being the same in each coil ( 9 amperes). These coils were oriented so that the theoretical zone of equal signals would cross the lower Potomac near Mathias Point. Characteristic signals were sent from each coil, the letter "A" being sent from one coil and the letter " $T$ " being sent from the other. These two coils are placed at an angle of $143.5^{\circ}$ with respect to each other. The bisector of this angle is a line on which the relative strength of the signals $A$ and $T$ should be equal. Any deviation from this line would cause one signal to increase in strength and the other to decrease proportionally.

The tests made aboard the Maple established without doubt the existence of a sector of equal signals. Owing to the difficulty of detecting very small changes of intensity between the two signals, there is a zone instead of a sharply defined line in which changes of signal strength are not apparent. This zone is clearly shown in Figure 7 , and by reference to the scale of miles it will be seen that at a distance of $50 \mathrm{~km}$ ( 3 I miles) the zone is approximately $I \frac{1}{4}$ miles wide. The border lines of this zone are much sharper than the center line; for example, changes in signal strength are noted more quickly and accurately, suggesting the use of the border line for navigational purposes instead of the theoretical equal signal line.

In this figure the zone of equal signals, as found from this test, and the line of equal signals, as derived theoretically (from the geometric position of the coils), are seen to check very closely. As the boat moved from $A$ to $B$ the relative strength of the signal $A$ and $T$ changes from $A$ greater than $T$ to $T$ greater than $A$. The signals were equal in strength while passing from $C$ to $D$. As mentioned above, this is caused by the difficulty in noting small changes in intensity of the two signals.

For the purpose of determining the value of this equisignal beacon system in aerial navigation the work was transferred from the Bureau of Standards to McCook Field, Dayton, Ohio, where the work could be more advantageously continued with the cooperation of the United States Army Air Service. 


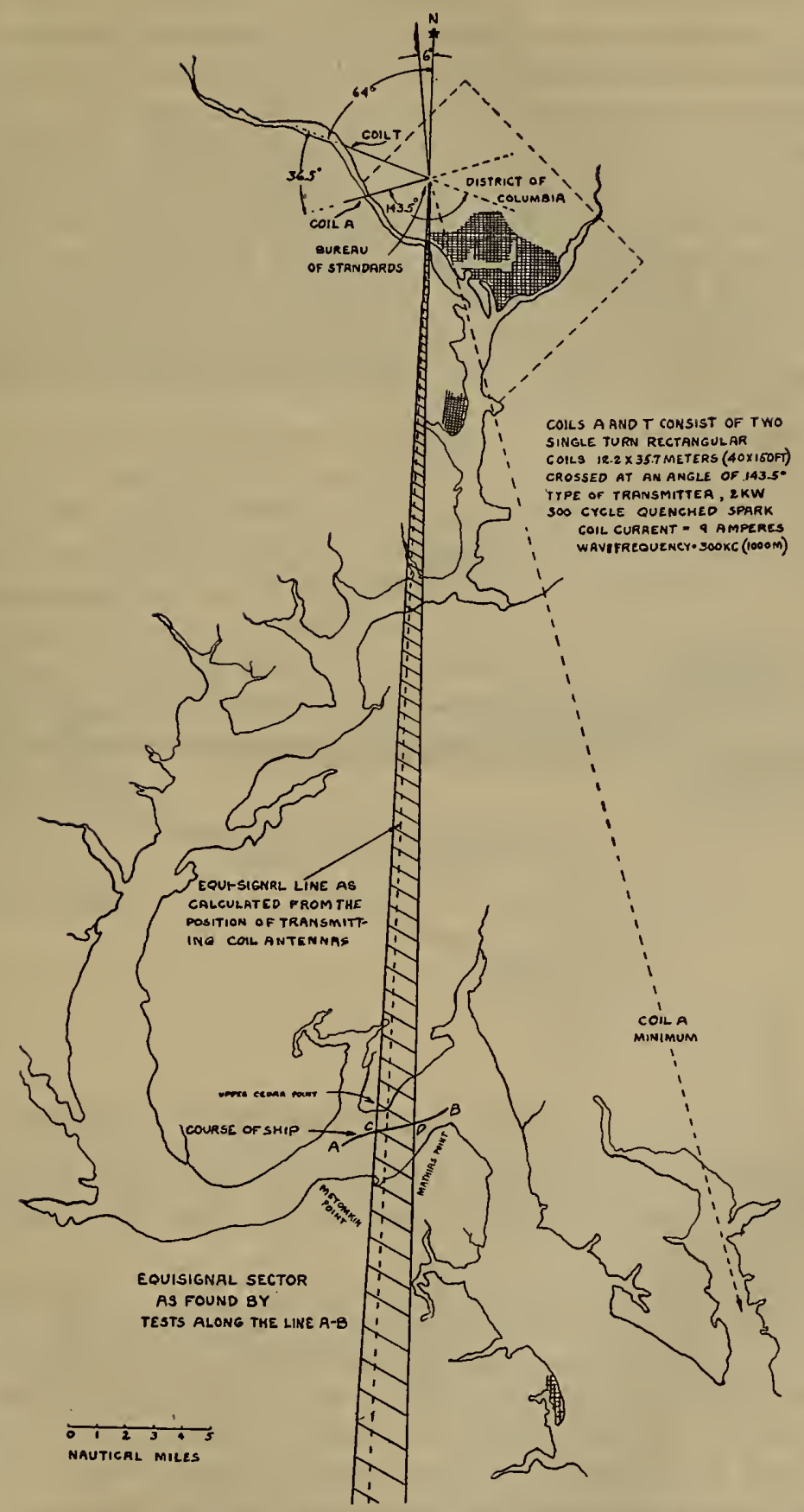

FIG. 7.-Chart illustrating results of equisignal double-coil antenna directive transmission tests conducted on lighthouse tender "Maple" May Ig, Ig2I, showing sector within which an airplane or a ship may hold its course by equisignal reception from the coils $A$ and $T$. 


\section{EXPERIMENTS CONDUCTED AT MCCOOK FIELD.}

(a) Transmitting Apparatus.-The crossed-coil antenna used at $\mathrm{McCook}$ Field consisted of two single-turn coil antennas of the approximate dimensions $\mathrm{I} 5.25$ by $36.6 \mathrm{~m} 50$ by $\mathrm{I} 20$ feet supported by three masts so placed that the angle between the coils was $135^{\circ}$. An automatic change-over switch alternately connected each coil to a standard 5-kilowatt 500-cycle quenched spark transmitting set. The connections used were the same as used at the Bureau of Standards and shown in Figures 2 and 6. When turned to 300 kilocycles $(1,000 \mathrm{~m})$, the current in the coil antenna was 15 amperes, but this was later increased to about

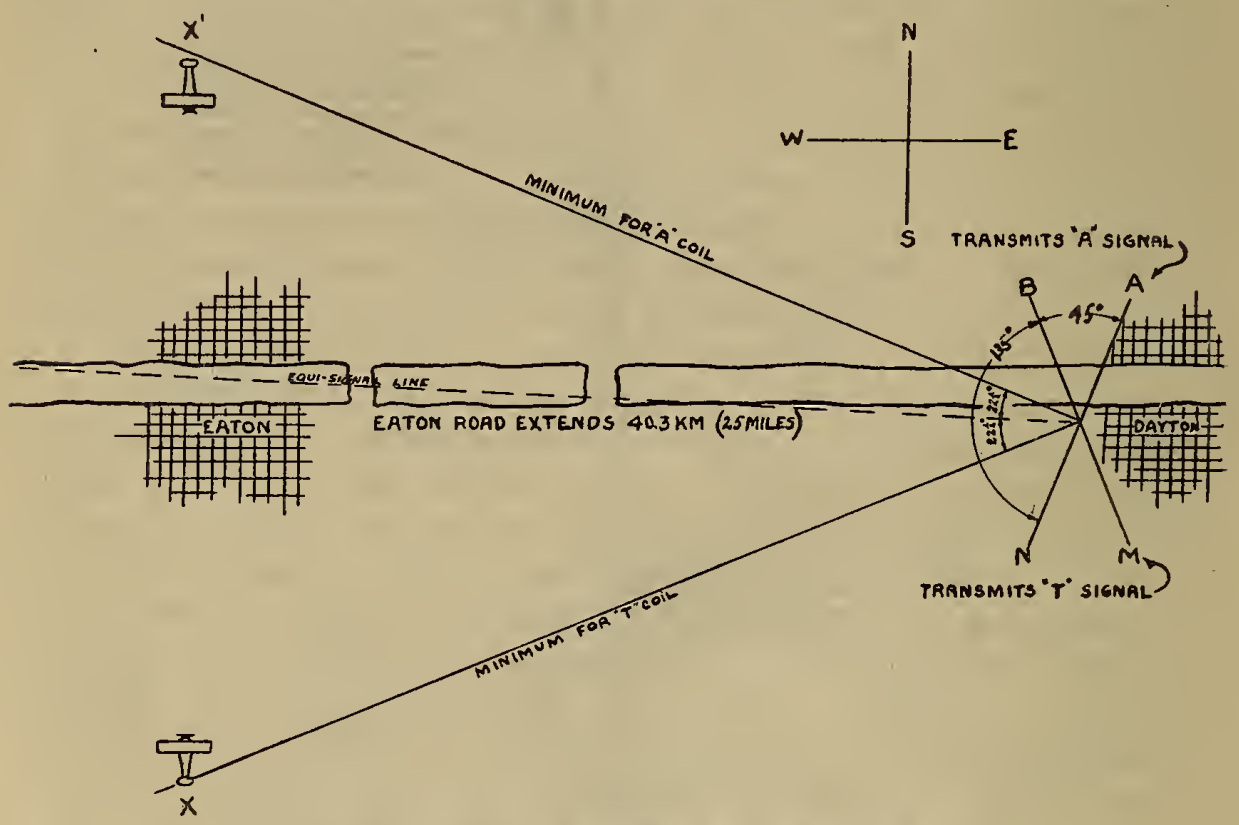

FiG. 8.-Double-coil antenna as installed at McCook Field, Dayton, Ohio.

I 8 amperes by using larger wire in the coils. The coils were oriented so that the line of equal signals extended almost due east-west (see fig. 8.)

(b) Receiving Apparatus Used on Ground.-A Signal Corps type SCR-108 radio truck was used in all ground tests. This type of truck has a completely inclosed body in which the apparatus is mounted and is equipped with a single rotating coil direction finder unit. The coil, which was about $1.37 \mathrm{~m}$ ( $4 \frac{1}{2}$ feet) square, was used in conjunction with a 7 -tube amplifier while receiving signals from the crossed-coil transmitting set at distances up to 50 miles. 
(c) Airplane Receiving Apparatus.-A De Haviland 4-B airplane was used in all the flying tests. The rear or gunner's cockpit housed the antenna reel and wire, inductively-coupled tuner, 7 -tube Signal Corps amplifier, and the necessary batteries. The fair lead projected through the flooring of the gunner's cockpit, allowing a wire to trail on the left side of the fuselage looking forward. In addition to the trailing wire, a coil of two turns of insulated wire extending from the trailing edge of the upper wing and landing gear to the rudder post could be connected to the amplifier and coupler by a d. p. d. t. switch.

(d) Ground Tests.-Ground tests similar to those conducted at the Bureau of Standards were made to determine the exact location of the equisignal zone in order that flying tests could be made more easily. Fortunately, a good road extended west of Dayton, and the equisignal line coincided roughly with this road, affording greater ease of observation than was possible at Washington. At points on this road $2 \mathrm{I}, 34,55,6 \mathrm{r}$, and $8 \mathrm{r} \mathrm{km}(\mathrm{I} 3,2 \mathrm{I}$, 34,38 , and $5 \mathrm{I}$ miles) distant from the transmitting station observations were made on crossroads running perpendicular to the equisignal line. The width of the zone at these points was found to be as follows:

TABLE 1.-Width of Equisignal Zone as Measured at Various Distances from the Crossed-Coil Transmitting Set.

\begin{tabular}{|c|c|c|c|c|}
\hline \multirow[t]{2}{*}{ Test. } & \multicolumn{2}{|c|}{$\begin{array}{l}\text { Distance from trans } \\
\text { milting station. }\end{array}$} & \multicolumn{2}{|c|}{ Width of equisignal. } \\
\hline & $\begin{array}{r}\text { Miles. } \\
13 \\
21 \\
34 \\
38 \\
51\end{array}$ & $\begin{array}{r}\mathrm{km} \\
21 \\
34 \\
55 \\
61 \\
82\end{array}$ & $\begin{array}{r}\text { Ft. } \\
360 \\
400 \\
400 \\
450 \\
500\end{array}$ & $\begin{array}{l}\text { m } \\
110 \\
222 \\
222 \\
137 \\
152\end{array}$ \\
\hline
\end{tabular}

In measuring the width of the zone at these points the following method was used. The signals were tuned in and the amplifier adjusted until the strength of the signals was of medium intensity. The truck was then driven back and forth on a line perpendicular to the equisignal line until the middle point was found; that is, where the intensities of the signals were equal. Then the truck was slowly driven north until the inequality of the signals became noticeable, this point being taken as one limit of the zone. The truck was then driven due south past the middle point of the zone until the inequality of the signals again became noticeable. This point was taken as the other limit of the zone, the distance between the two limits as determined was taken as the width of the zone. 
The equisignal zone so determined was found to extend due west, not exceeding $152 \mathrm{~m}$ (500 feet) in width at any point up to $80 \mathrm{~km}$ (50 miles) from the transmitting station. As the distance from the transmitting station increased the sharpness of the zone decreased, which necessitated closer observation to determine the exact width of the zone. It is interesting to note that observations could not be made close to overhead wires of any kind or in the lee of a high hill or wooded section. It was found that wires running parallel to and in the immediate vicinity of the equisignal zone have the effect of blending the two signals, distorting the position of the zone, and in many cases doubling the strength of both signals.

It was found during these ground tests that unequal current values in the transmitting loops caused a shift in the position of the equisignal zone. On one occasion, a difference of $\mathrm{I} / 2 \mathrm{am}-$ peres caused a shift of $610 \mathrm{~m}(2,000$ feet $)$ at a distance of 80 $\mathrm{km}$ (50 miles) from the transmitting set.

(e) Flying Tests.-Assuming that the trailing wire antenna is nondirectional, the results obtained in the air would be as follows: The airplane being northwest of the cross-coil antennas (at point $X^{\prime}$, fig. 8) would receive a very loud signal from coil antenna $B M$, since it is near the maximum of coil $B M$ and near the minimum of coil $A N$. Proceeding southward the ratio of the signal intensity of the two coil antennas would decrease, the signals becoming equal at any point on the line bisecting the large angle between the coil antennas. This line is referred to in the preceding discussion as the equisignal zone. Leaving the equisignal zone and flying farther south, the signals will again become unequal, the signals from coil $A N$ becoming much louder than the signals from coil $B M$, since the airplane is now nearing the maximum of coil $A N$ and the minimum of coil $B M$. In the ground tests the results as outlined above were actually obtained, using a coil antenna at the portable receiving set.

On the airplane which used a 20o-foot trailing wire antenna the results obtained were markedly different, owing to the directional characteristics of the trailing wire. These tests showed that the signals were stronger when the airplane was flying away from the transmitting station than when flying toward it. This is contrary to the experience of other observers. This effect resulted in an apparent shifting of the equisignal zone in the direction of flight when flying across the equisignal zone. The shift was greatest when the airplane was flown at right angles to the equisignal line. When flying to or from the transmitting coils the shift was not noticed. 
Again, referring to Figure 8 , assume an airplane to be at point $X^{\prime}$ as before. The signals actually received at this point bore the relation $A<T$; that is, the signals from coil $B M$ were much stronger than those received from coil $A N$. Flying due south the signals gradually became equal, but at a point farther south of the equisignal zone than was found by the ground tests. Still flying south the signals gradually became unequal, and at point $X$ the signal from $A N$ was much stronger than the signal from $B M$. Turning the airplane $180^{\circ}$ and flying due north, as shown at point $X$, the signals from $A N$ became very loud, while the signals from $B M$ became very weak. Still flying north the signals gradually became equal in strength, but at a point farther north of the zone than was found by ground experiments; that is, if the equisignal zone is approached from the north its apparent position is to the south of its actual location; if approached from the south, its apparent position is to the north of the actual location.

This apparent displacement of the equisignal zone in the direction of flight was more marked the greater the altitude of flight. Twenty miles distant from the transmitting coils this shift at an altitude of $305 \mathrm{~m}$ ( $\mathbf{r}, 000$ feet) was found to be about I mile; that is, an airplane flying in one direction across the equisignal zone found this zone displaced from its true position about I mile in the direction of flight; an airplane flying in the opposite direction found the equisignal zone displaced I mile in the new direction of flight. At 6 I0 $\mathrm{m}(2,000 \mathrm{feet})$ this zone displacement appeared to be about 2 miles, and at 91 $5 \mathrm{~m}(3,000$ feet) it appeared to be about 4 miles. At all altitudes, however, with the airplane in a stall so that the trailing antenna hung vertically or when the airplane was flying toward or away from the transmitting coils there was no zone displacement, the zone being located in the position determined by ground tests.

The result of these tests, in which a light antenna weight and a $61 \mathrm{~m}$ (200 feet) trailing wire were used, showed that the apparent shift in the equisignal zone was due entirely to the type of receiving antenna used and its inclination to the vertical. By using a short trailing wire with a much heavier weight the antenna hung in a nearly vertical position, thus eliminating the zone displacement effect to a large extent. Such an antenna is best suited for this type of reception, as any ambiguities arising from an apparent shift in the equisignal zone when the airplane is turned are practically overcome. The use of a coil antenna 
in place of a trailing wire is equally effective in this respect, but can not be worked over as great a distance. Recent tests with a short trailing wire and heavy weight have shown this method to be effective in enabling a pilot to guide his airplane into Dayton from a distance of $\mathrm{x} 6 \mathrm{r} \mathrm{km}$ (100 miles).

One of the great advantages of this system over the method employing a radio direction finder on the airplane or on shipboard

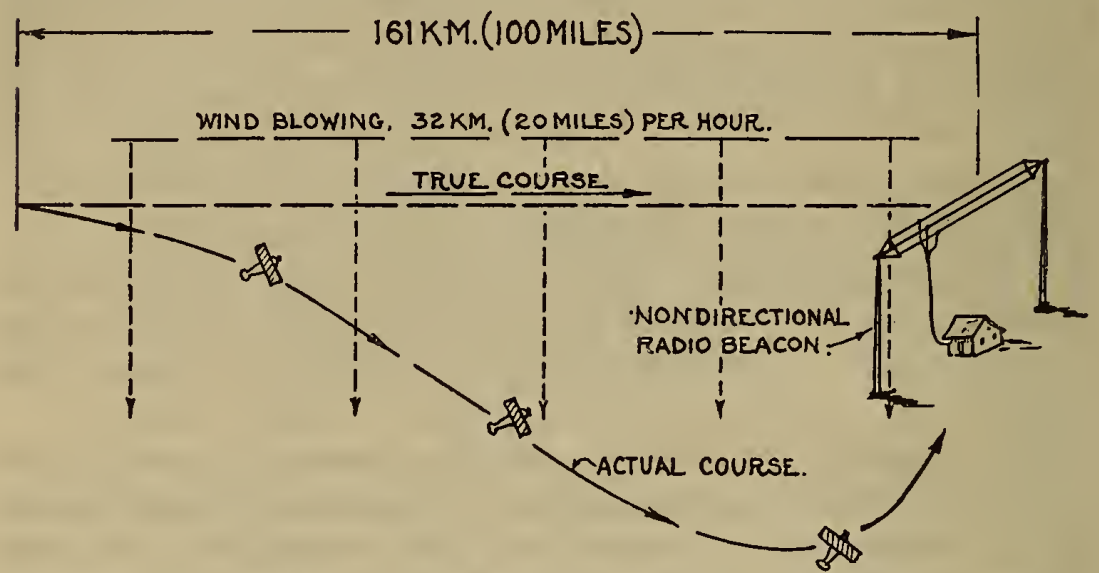

FiG. 9.-Effect of wind drift on an airplane.

Shows course followed by pilot of the airplane when flying at $16 \mathrm{r} \mathrm{km}$ (100 miles) per hour and navigating by means of direction finder or magnetic compass bearings.

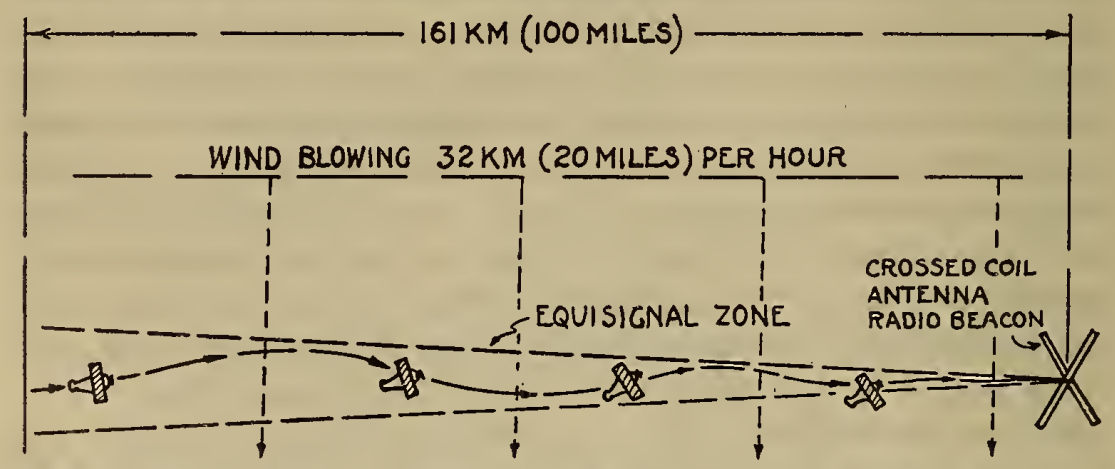

FIG. Io.-Method of eliminating effect of wind drift on an airplane by the use of a crosscoil antenna radio beacon.

is that the effect of side drift may be immediately noticed and corrected for by heading the airplane at the correct angle into the wind, thus enabling a pilot to maintain a straight course along the line of direction to the transmitting-coil beacons. In aerial navigation this is much more important than in marine navigation, as the effect of side drift due to cross winds is often very marked. This effect is illustrated in Figure 9. The effect of cross 
winds on an airplane navigating by means of magnetic or ordinary radio direction finder bearings is shown in Figure 9. It will be seen that under these conditions the airplane may deviate considerably from its true course. Figure ro illustrates how, by means of the equisignal crossed-coil radio beacon, an airplane may maintain a straight course regardless of cross winds and visibility conditions.

\section{SUMMARY.}

The crossed-coil antenna directive radio beacon consists of twocoil antennas crossed at an angle of about $135^{\circ}$ with respect to each other, signals being transmitted alternately from each coil antenna. A receiving set located anywhere on the line bisecting the angle between the two coils alternately receives signals from each coil. The intensity of the two signals is the same. At any point not on the bisector of the angle between the coils signals of unequal intensity are received, the difference in intensity depending on the location of the receiving set. When used for beacon purposes, an aircraft or ship equipped with the ordinary type of receiving set may keep on a direct line to the beacon by navigating so that the signals received from each coil are of equal intensity.

The apparatus used is described and an account of its experimental development given. Tests made both on the ground and in the air indicate that this method of guiding ships and airplanes has advantages over other methods in that ( $\mathrm{I}$ ) no special receiving equipment is needed, and (2) a straight course over a definite route may be constantly maintained. (In other methods unless frequent bearings are taken wind drift or water currents introduce error.)

The authors are glad to acknowledge the cooperation and assistance of P. D. Lowell, J. L. Bernard, and F. M. Baer, and the officers of the Signal Corps and Army Air Service in conducting this work.

WASHINGTON, September 8, 1923. 




